\title{
Identification of cephalopod species from the North and Baltic Seas using morphology, COI and 18S rDNA sequences
}

\author{
Katharina Gebhardt ${ }^{1} \cdot$ Thomas Knebelsberger $^{2}$
}

Received: 10 October 2014/Revised: 14 April 2015/Accepted: 20 April 2015/Published online: 5 May 2015

(C) Springer-Verlag Berlin Heidelberg and AWI 2015

\begin{abstract}
We morphologically analyzed 79 cephalopod specimens from the North and Baltic Seas belonging to 13 separate species. Another 29 specimens showed morphological features of either Alloteuthis mediaor Alloteuthis subulata or were found to be in between. Reliable identification features to distinguish between A. media and A. subulata are currently not available. The analysis of the DNA barcoding region of the COI gene revealed intraspecific distances (uncorrected $p$ ) ranging from 0 to $2.13 \%$ (average $0.1 \%$ ) and interspecific distances between 3.31 and $22 \%$ (average 15.52\%). All species formed monophyletic clusters in a neighbor-joining analysis and were supported by bootstrap values of $\geq 99 \%$. All COI haplotypes belonging to the 29 Alloteuthis specimens were grouped in one cluster. Neither COI nor $18 \mathrm{~S}$ rDNA sequences helped to distinguish between the different $\mathrm{Al}$ loteuthis morphotypes. For species identification purposes, we recommend the use of COI, as it showed higher bootstrap support of species clusters and less amplification and sequencing failure compared to $18 \mathrm{~S}$. Our data strongly support the assumption that the genus Alloteuthis is only
\end{abstract}

Communicated by H.-D. Franke.

Electronic supplementary material The online version of this article (doi:10.1007/s10152-015-0434-7) contains supplementary material, which is available to authorized users.

Thomas Knebelsberger

tknebelsberger@senckenberg.de

1 Department of Biology and Environmental Sciences, Carl von Ossietzky University of Oldenburg, Carl-vonOssietzky-Straße 9-11, 26129 Oldenburg, Germany

2 Senckenberg am Meer, German Center for Marine Biodiversity Research (DZMB), Südstrand 44, 26382 Wilhelmshaven, Germany represented by a single species, at least in the North Sea. It remained unclear whether this species is A. subulata or $A$. media. All COI sequences including important metadata were uploaded to the Barcode of Life Data Systems and can be used as reference library for the molecular identification of more than $50 \%$ of the cephalopod fauna known from the North and Baltic Seas.

Keywords Cephalopoda - Species identification . Morphology $\cdot$ DNA barcoding $\cdot$ mtDNA $\cdot 18 \mathrm{~S}$ rDNA

\section{Introduction}

Cephalopods play a significant role in marine ecosystems, both as consumers and as prey (Hastie et al. 2009). Approximately 30 cephalopod species have been recorded in the northeastern Atlantic and adjacent waters, including 18 squids (Teuthida), seven bobtail squids (Sepiolida), three cuttlefish (Sepiida) and 10 octopuses (Octopoda) (Hastie et al. 2009). Some of these are of economic and commercial interest, such as Eledone cirrhosa Lamarck, 1798, Loligo vulgaris Lamarck, 1798, Loligo forbesii Steenstrup, 1857, Todarodes sagitattus Lamarck, 1798, Illex coindetii Vérany, 1839 and Todaropsis eblanae Ball, 1841 (Hastie et al. 2009). The identification of cephalopod species is traditionally based on the examination of morphological features using identification keys or species descriptions. Two groups of North Sea cephalopods are especially challenging concerning morphological identification; these are the Sepiolida, which are likely misidentified due to their small size and physical resemblance (Groenenberg et al. 2009; Goud and De Heij 2012) and the squids of the genus Alloteuthis, namely Alloteuthis subulata Lamarck, 1798 and Alloteuthis media Linnaeus, 1758. The latter two 
lack confident distinguishing features, questioning their taxonomic status as different species (Anderson et al. 2008; Laptikhovsky et al. 2002).

Where morphological differentiation of species is difficult, molecular data might lead to new conclusions. In this context, a defined region of the cytochrome $c$ oxidase subunit I (COI) gene has been designated to serve as "DNA barcode" for species identification, as intraspecific variability is considerably lower than the distance to the nearest relative among most species (Hebert et al. 2003a, b). The explicit divergence between intra- and interspecific genetic distances (barcoding gap) is a quality criterion for barcoding in general and a measurement for the accuracy of this method (Hebert et al. 2004).

DNA barcoding of cephalopods has already successfully been applied to the identification of octopuses and various other cephalopod species from Asian waters and the Southern Ocean (Dai et al. 2012; Kaneko et al. 2011; Allcock et al. 2011; Undheim et al. 2010; Badhe et al. 2013). So far, barcoding of cephalopods from the North Sea has focused on bobtail squids (Groenenberg et al. 2009).

Furthermore, the analysis of molecular data enables the detection of cryptic diversity. A study on the molecular phylogeny of Sepiolinae using the mitochondrial cytochrome $c$ oxidase subunit I (COI) recently discovered cryptic species from the North Sea (Groenenberg et al. 2009). Specimens initially identified as Sepiola atlantica d'Orbigny, 1842 split into two distinct groups, the original S. atlantica and the previously undescribed species Sepiola tridens De Heij and Goud 2010. Thorough morphological and ecological investigations of S. atlantica and $S$. tridens revealed consistent differences between these two closely related species.

While COI offers benefits as a genetic marker for species identification, it may cause problems in some cases. Introgressive hybridization or incomplete lineage sorting may lead to haplotype sharing between closely related species (Conflitti et al. 2012; Funk and Omland 2003), as COI is maternally inherited. Additionally, the analysis of nuclear copies of mitochondrial DNA (NUMTs) can lead to an overestimation of species numbers (Song et al. 2008). As NUMTs contain stop codons, indels or non-synonymous mutations, they can easily be detected (Strugnell and Lindgren 2007).

In cases where COI fails for species delineation, supplementary markers can be useful. A promising candidate is the $18 \mathrm{~S}$ rDNA gene. Although $18 \mathrm{~S}$ is one of the most frequently used markers in phylogenetic studies (e.g., Field et al. 1988; Aguinaldo et al. 1997; Halanych 2004; Telford et al. 2005), it is also useful for species identification purposes (Raupach et al. 2010). The high amount of $18 \mathrm{~S}$ rDNA in eukaryotic cells and the highly conserved flanking regions, that allow the use of universal primers, make it relatively easy to amplify (Hillis and Dixon 1991). The $18 \mathrm{~S}$ rDNA fulfills the same function in every species and is thus exposed to similar selective forces in all organisms, evolving at a comparably similar rate (Moore and Steitz 2002).

The success of a worldwide species identification system based on DNA barcodes is dependent on the availability and quality of barcode reference libraries. In this context, an open-access informatics workbench, the Barcode of Life Data Systems (BOLD, http://www.boldsystems.org/), was launched in 2007 (Ratnasingham and Hebert 2007). The development of a DNA barcode database for Cephalopoda was first proposed at the cephalopod international advisory council symposium in 2006 (Strugnell and Lindgren 2007). Currently, 4775 cephalopod barcode sequences belonging to 418 different species are recorded on BOLD, representing approximately $40 \%$ of the known cephalopod species. This study aimed at establishing a reliable DNA barcode database of cephalopod species from the North and Baltic Seas, based on morphologically identified material. COI sequences were uploaded to BOLD for comparison with public data. Additionally, we tested the performance of $18 \mathrm{~S}$ rDNA sequences as an alternative approach for species identification purposes.

\section{Materials and methods}

\section{Sampling}

A total of 108 cephalopod specimens from the North and Baltic Seas were examined for this study (Fig. 1, Table S1). Specimens were collected during several cruises of the Thünen-Institute of Sea Fisheries (Hamburg, Germany) with the research vessels Solea and Walther Herwig III between December 2009 and August 2012. Voucher specimens and tissue samples, as well as DNA extracts, were stored by using unique identifiers (MT numbers shown in Figs. 4, 5, and Table S1) at the German Center for Marine Biodiversity Research (DZMB; Senckenberg am Meer, Wilhelmshaven, Germany). DNA sequences, metadata and specimen images were uploaded to BOLD in the corresponding project folder "Barcoding Northeast Atlantic Cephalopoda" (BNEAC). All sequences were deposited in GenBank under the accession numbers KM517882KM517947 (COI) and KP136800-KP136827(18S rDNA).

\section{Morphological species identification}

For morphological a priori identification, electronic and printed identification keys (Hayward and Ryland 1995; Marine Species Identification portal http://species-identifi cation.org) and species descriptions (Hastie et al. 2009; De 

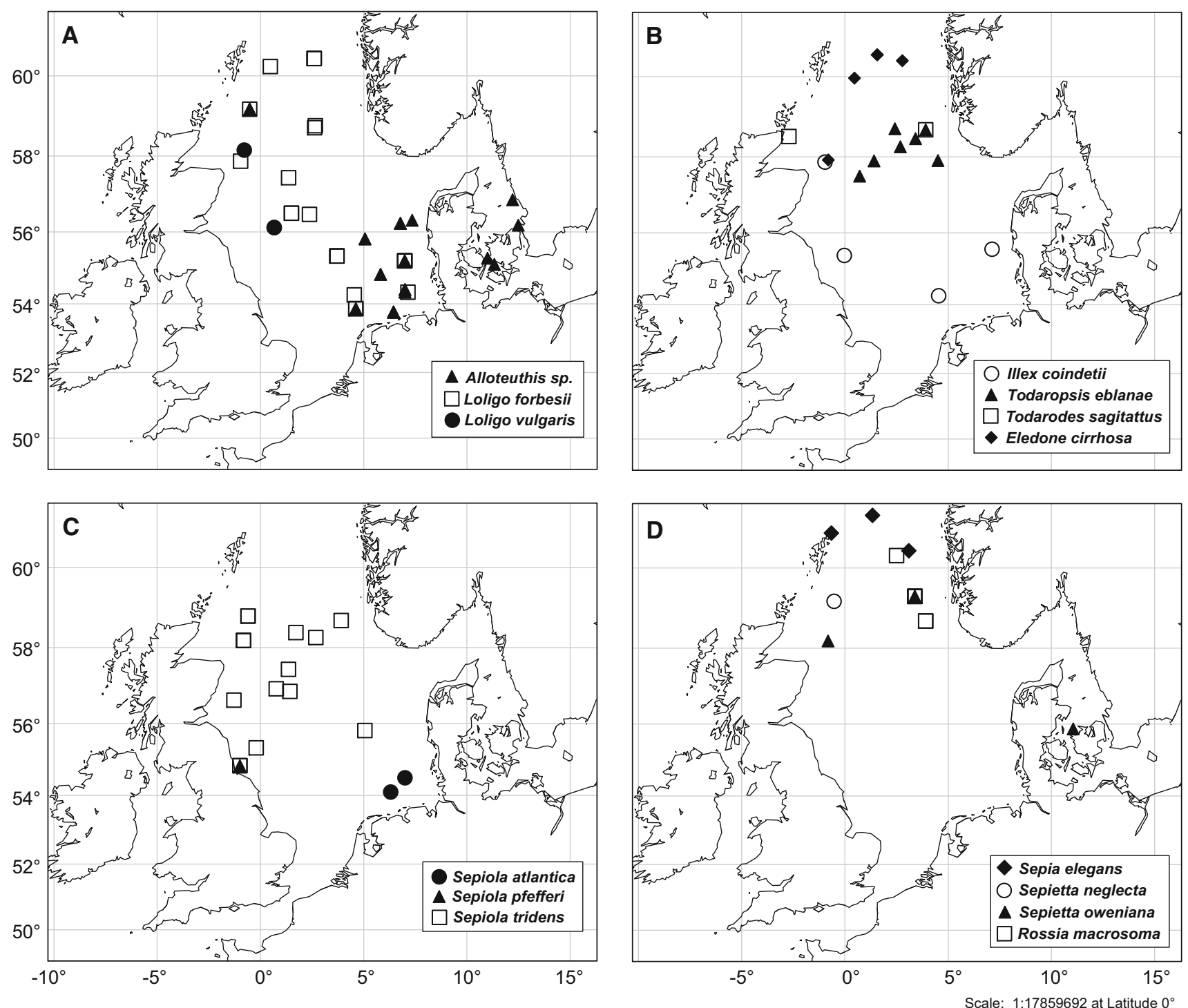

Fig. 1 Sampling sites of cephalopods from the North and Baltic Seas. a Myopsida, b Oegopsida and Eledone cirrhosa, c Sepiola, d Sepiolida. Same scale in $\mathbf{a}-\mathbf{d}$

Heij and Goud 2010; Goud and De Heij 2012; Jereb and Roper 2005, 2011) were used. For Alloteuthis squids, further literature was required (Anderson et al. 2008; Laptikhovsky 2005). Specimens were examined either by eye or by using a M125 binocular (Leica), and measurements were taken with a calliper. Common informative structures for species identification were the tentacular clubs with suckers, the number of sucker rows, the hectocotylus of the males and in case of Alloteuthis squid the length and form of fin and tail.

\section{DNA extraction and amplification of COI}

DNA from all 108 specimens was extracted using DNeasy Blood and Tissue Kit (Qiagen) following a protocol of
Knebelsberger and Stöger (2012). A 658-base pair (bp) fragment of COI was amplified using universal metazoan primers LCO1490 and HCO2198 (Table 1). PCR products were obtained using three protocols on an Eppendorf Mastercycler $^{\circledR}$ pro. Each PCR contained $20.125 \mu \mathrm{l} \mathrm{H}_{2} \mathrm{O}$, $2.25 \mu \mathrm{l} 10 \times$ PCR buffer, $0.5 \mu \mathrm{l}$ dNTP $(2 \mathrm{mM}$ each), $0.125 \mu \mathrm{l}$ Taq polymerase ( $5 \mathrm{U} / \mu \mathrm{l}$, Qiagen), $0.25 \mu \mathrm{l}$ of each primer $(10 \mathrm{pM})$ and $1.5 \mu \mathrm{l}$ DNA template. The temperature profile consisted of an initial step for $2 \mathrm{~min}$ at $94{ }^{\circ} \mathrm{C}$, followed by 35 cycles of $30 \mathrm{~s}$ at $94{ }^{\circ} \mathrm{C}, 30 \mathrm{~s}$ at $42{ }^{\circ} \mathrm{C}$ and $60 \mathrm{~s}$ at $72{ }^{\circ} \mathrm{C}$. The final extension was at $72{ }^{\circ} \mathrm{C}$ for $10 \mathrm{~min}$. Unsuccessful reactions were repeated with the following modifications: $2 \mu \mathrm{H}_{2} \mathrm{O}$ were replaced by the same volume of Q-Solution (Qiagen), and the PCR was performed with a decreased annealing temperature of $40{ }^{\circ} \mathrm{C}$ and 40 cycles. If 
Table 1 Primers LCO1490 and HCO2198 were used for PCR and sequencing of COI. 18A1 and 1800 amplified the whole 18S rDNA; F1, F2, $\mathrm{R} 1$ and R2 served as internal primers

\begin{tabular}{llll}
\hline Primer & Sequence (in 5'-3' direction) & Orientation & References \\
\hline LCO1490 & GGTCAACAAATCATAAAGATATTGG & forward & Folmer et al. (1994) \\
HCO2198 & TAAACTTCAGGGTGACCAAAAAATCA & reverse & Folmer et al. (1994) \\
18 A1 & CTGGTTGATCCTGCCAGTAGTCATATGC & forward & Wollscheid and Wägele (1999) \\
1800 & GATCCTTCCGCAGGTTCACCTACG & reverse & Wollscheid and Wägele (1999) \\
F1 & AGCAGCCGCGGTAATTCCAGCT & forward & Laakmann et al (2013) \\
F2 & GAAACTTAAAGGAATTGACGGAA & forward & Laakmann et al. (2013) \\
R1 & CCTTCCGTCAATTCCTTTAAGT & reverse & Laakmann et al. (2013) \\
R2 & AGCTGGAATTACCGCGGCTGCT & reverse & Laakmann et al. (2013) \\
\hline
\end{tabular}

All six primers were used for sequencing of the whole $18 \mathrm{~S}$ rDNA fragment

necessary, PCRs were finally carried out using Illustra $^{\mathrm{TM}}$ Ready-To-Go PCR Beads (GE Healthcare), $20 \mu \mathrm{l} \mathrm{H}_{2} \mathrm{O}$, $0.5 \mu \mathrm{l}$ of each primer $(10 \mathrm{pM}), 4 \mu \mathrm{l}$ DNA template and the temperature profile of the modified protocol.

\section{Amplification of $18 \mathrm{~S}$}

A 1800-bp region of $18 \mathrm{~S}$ was amplified using the primers 18A1 and 1800 (Table 1). Each sample contained $29 \mu 1$ $\mathrm{H}_{2} \mathrm{O}, 4 \mu \mathrm{l} 10 \times$ PCR buffer, $4 \mu \mathrm{l}$ dNTP (2 mM each), $0.2 \mu \mathrm{l}$ Taq polymerase ( $5 \mathrm{U} / \mu \mathrm{l}$, Qiagen), $0.4 \mu \mathrm{l}$ of each primer $(10 \mathrm{pM})$ and $2 \mu \mathrm{l}$ DNA template. The temperature profile consisted of an initial step for $5 \mathrm{~min}$ at $94{ }^{\circ} \mathrm{C}$, followed by 36 cycles of $45 \mathrm{~s}$ at $94{ }^{\circ} \mathrm{C}, 50 \mathrm{~s}$ at $50{ }^{\circ} \mathrm{C}$ and $200 \mathrm{~s}$ at $72{ }^{\circ} \mathrm{C}$. The final extension was at $72{ }^{\circ} \mathrm{C}$ for $10 \mathrm{~min}$. Unsuccessful reactions were first repeated with a decreased annealing temperature of $42{ }^{\circ} \mathrm{C}$, and if necessary, the number of cycles was increased to 50. In cases where the previous protocols failed, PCRs were carried out using Illustra ${ }^{\mathrm{TM}}$ Ready-To-Go PCR Beads (GE Healthcare), $37.5 \mu \mathrm{H}_{2} \mathrm{O}, 0.4 \mu \mathrm{l}$ of each primer (10 pM), $2 \mu \mathrm{l}$ DNA template and 40 PCR cycles.

\section{Purification and sequencing}

Size and quality of PCR products were checked via agarose gel electrophoresis prior to purification and sequencing. The samples were enzymatically purified using Exonuclease I (EXO, $20 \mathrm{U} / \mu \mathrm{l})$ and Shrimp Alkaline Phosphatase (SAP, $1 \mathrm{U} / \mu \mathrm{l}$ ) (both Thermo Scientific). For COI, $23 \mu \mathrm{l}$ (or the leftover amount) of each PCR product was added by $5 \mu \mathrm{l} \mathrm{SAP}$ and $1.25 \mu \mathrm{l}$ EXO. For $18 \mathrm{~S}, 38 \mu \mathrm{l}$ of PCR products was mixed with $7.6 \mu \mathrm{l} \mathrm{SAP}$ and $1.9 \mu \mathrm{l}$ EXO. The suspensions were then incubated at $37{ }^{\circ} \mathrm{C}$ for $15 \mathrm{~min}$, followed by $20 \mathrm{~min}$ at $75^{\circ} \mathrm{C}$. Purified PCR products were sent to Macrogen Inc. (Amsterdam, Netherlands) for sequencing. For COI, PCR primers were used for sequencing (Table 1). Products of $18 \mathrm{~S}$ were sequenced using PCR primers plus the four internal primers F1, F2, R1 and R2 (Table 1).

\section{Sequences from GenBank}

Nineteen COI sequences (Table S2) of Sepiolida from the North Sea, Northeast Atlantic Ocean and the Mediterranean were mined from GenBank (http://www.ncbi.nlm. nih.gov/genbank/) in order to verify the morphological identification. Ten sequences originated from a study by Groenenberg et al. (2009), who demonstrated wrong species assignments for a high percentage of the available Sepiolida sequences in GenBank. Based on their conclusions, sequences were selected carefully and only further nine COI barcodes from GenBank were included in our study. For all other available Sepiolida sequences, a preliminary NJ analysis (data not shown) demonstrated wrong species assignment.

\section{Data analysis}

Electropherograms received from Macrogen were assembled and edited using Geneious 6.1.6 created by Biomatters (http://www.geneious.com/). COI consensus sequences were aligned by MUSCLE (Edgar 2004) using the default settings in MEGA 5.2 (Tamura et al. 2011). Consensus sequences as well as trace files were uploaded to the BNEAC project on BOLD. Sequence statistics were performed using BOLD's "Sequence Composition" analysis tool (sequence length $\geq 50 \mathrm{bp}$, no filters, GC \% calculated on first, second and third codon positions and all positions combined), and distances to the nearest neighbor (NN) were calculated using the "Barcode Gap" analysis tool (pairwise distance, aligned by MUSCLE, sequence length $\geq 50 \mathrm{bp}$, no filters, pairwise deletion). The barcoding gap is a quality criterion for barcoding in general and a measurement for the accuracy of this method (Meyer and Paulay 2005). Intraspecific variability is considerably 
lower than the distance to the nearest relative among most species (Hebert et al. 2003b). This difference between the highest intraspecific and the lowest interspecific (nearest neighbor) genetic distance is called barcoding gap (Meyer and Paulay 2005). The absence of a barcoding gap can be due to misidentification, DNA contamination or a real evolutionary background (hybridization, incomplete lineage sorting, recent speciation).

Uncorrected pairwise p-distances for COI were generated in MEGA 5.2 (variance estimation method: none; substitution type: nucleotide; substitutions including transitions and transversions; gaps/missing data treatment: pairwise deletion). Pairwise distances were visualized as histograms using PAST 2.17 (Hammer et al. 2001). A neighbor-joining (NJ) analysis (Saitou and Nei 1987) was performed (substitution type: nucleotide; substitutions including transitions and transversions; gaps/missing data treatment: pairwise deletion on first, second and third codon positions plus noncoding sites) based on $\mathrm{p}$-distances with 10,000 bootstrap replicates (Efron 1982; Felsenstein 1985) for all COI data from this study and 19 Sepiolida sequences mined from GenBank (Table S2).

The $18 \mathrm{~S}$ consensus sequences were aligned in MEGA 5.2 using MUSCLE under default settings. A NJ tree was generated in MEGA 5.2 (substitution type: nucleotide; substitutions including transitions and transversions; gaps/ missing data treatment: pairwise deletion on first, second and third codon positions plus noncoding sites) based on p-distances with 10,000 bootstrap replicates.

\section{Results}

\section{Morphological species identification}

All cephalopod specimens in this study could be successfully identified and assigned to 13 different species based on morphological features, except those belonging to the genus Alloteuthis. The specimens representing the Oegopsida, the squids of the genus Loligo and the species $E$. cirrhosa, Sepia elegans Blainville, 1827 and Rossia macrosoma Delle Chiaje, 1830 were easily identified by distinct morphological features.

Within the genus Alloteuthis, we found three different morphotypes: specimens displayed features of either $A$. subulata or A. media or a mixture of both species. As a consequence, all Alloteuthis specimens were assigned to Alloteuthis sp.

\section{DNA barcoding}

A total of 108 PCR products obtained from the COI barcoding gene could be successfully sequenced in both directions. The sequences were composed of $33.01 \% \mathrm{GC}$ $( \pm 0.17 \% \mathrm{SE}, \min =30.41 \%, \max =36.78 \%)$, not including stop codons, insertions and deletions. The sequence alignment was 658 bp long; the mean consensus sequence length was $651 \mathrm{bp}$. Of the 108 sequences, $89.1 \%$ reached the full fragment length of $658 \mathrm{bp}$. The sequence length of one Todarodes sagittatus specimen was 311 bp; however, it remained in the analysis as there was only one other conspecific sequence available.

The analysis of the uncorrected pairwise p-distances showed a clear difference between intra- and interspecific distance values. Intraspecific distances ranged from 0 to $2.13 \%$, while interspecific distances varied between 3.31 and $22 \%$ (Table 2). By plotting the frequencies of all intra- and interspecific distances (Fig. 2), the present study showed a clear gap between all intra- and interspecific distances without any overlaps.

Genetic distances increased with the taxonomic level, being smallest within species (0-2.13\%), followed by genus (3.31-9.92\%), family (8.97-17.32\%), order $(15.53-17.17 \%)$ and finally class (12.80-22.02\%) (Table 2). Distances at order level comprise only specimens of Sepiolida represented by the two families Sepiolidae and Sepiidae.

In each species, the maximum intraspecific distance was considerably lower than the distance to the nearest neighbor, resulting in explicit barcoding gaps (Table 3). The latter ranged from $3.41 \%$ (between $S$. atlantica and $S$. tridens) up to $19.20 \%$ (between E. cirrhosa and Sepiola pfefferi Grimpe 1921). The results were demonstrated by plotting the maximum intraspecific distance of each species against the distance to the nearest neighbor (Fig. 3). Two singleton species were not considered for barcoding gap analysis, as they lack intraspecific distance values. However, both species may exhibit pronounced barcoding gaps too, as S. pfefferi differed by $8.59 \%$ and Sepietta neglecta Naef, 1916 by $7.91 \%$ from their NN.

The NJ analysis of the COI sequence data showed a well-resolved topology with 13 distinct species clusters and no haplotype sharing between species (Fig. 4). Species clades were supported by bootstrap values $\geq 99 \%$. All sequences assigned to Alloteuthis sp. clustered together as well. Alloteuthis specimens morphologically identified as belonging rather than $A$. media or A. subulata, or those exhibiting morphological features of both species cannot be distinguished using the COI approach. For five species, barcodes from GenBank were added to our dataset to confirm the morphological identification of Sepiolida, which are difficult to identify based on morphological features. The NJ analysis confirmed the results of our morphological identification, resulting in distinct species clusters with $100 \%$ bootstrap support for all sepiolid species (Fig. 4). We confidently demonstrated here that the 
Table 2 Summary of uncorrected pairwise $(p)$ distances at different taxonomic levels

\begin{tabular}{lcrlcrr}
\hline $\begin{array}{l}\text { Comparisons } \\
\text { within }\end{array}$ & $\begin{array}{l}\text { Number of } \\
\text { specimens }\end{array}$ & Taxa & $\begin{array}{l}\text { Number of } \\
\text { comparisons }\end{array}$ & $\begin{array}{l}\text { Minimum distance } \\
(\%)\end{array}$ & $\begin{array}{l}\text { Maximum distance } \\
(\%)\end{array}$ & $\begin{array}{l}\text { Mean Dist } \pm \text { SD } \\
(\%)\end{array}$ \\
\hline Species & 106 & 12 & 858 & 0.00 & 2.13 & $0.11 \pm 0.16$ \\
Genus & 50 & 3 & 123 & 3.31 & 9.92 & $7.81 \pm 2.65$ \\
Family & 100 & 3 & 1091 & 8.97 & 17.32 & $12.64 \pm 2.36$ \\
Order & 35 & 1 & 96 & 15.53 & 22.02 & $16.46 \pm 0.36$ \\
Class & 108 & 1 & 3574 & 12.80 & $16.61 \pm 1.75$ \\
\hline
\end{tabular}

Fig. 2 Uncorrected p-distances; intraspecific distances in dark gray, interspecific distances in light gray. The enlarged cutaway view emphasizes on the "global" barcoding gap (gray area) between all intra- and interspecific distances

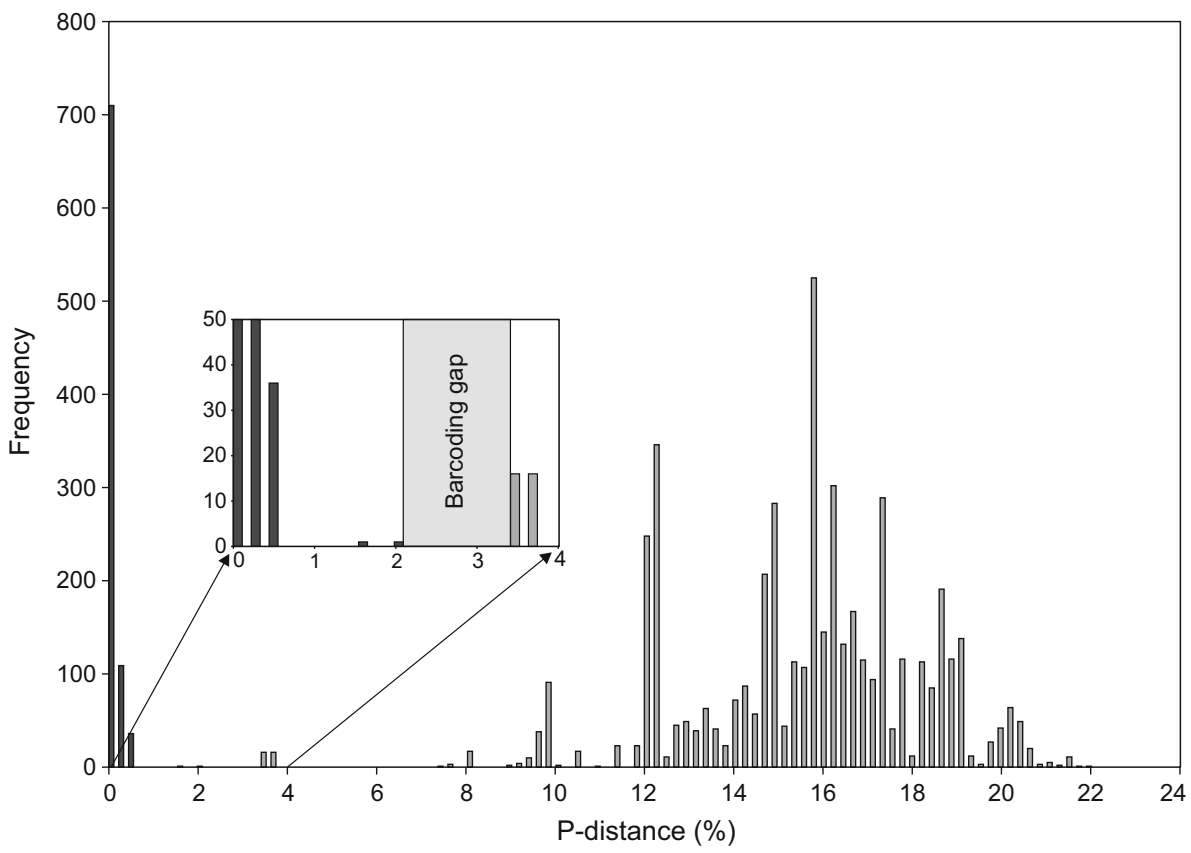

members of the genera Sepiola and Sepietta can be clearly distinguished using DNA barcode sequences.

\section{$18 S$ rDNA sequence analysis}

The analysis of the $18 \mathrm{~S}$ rDNA sequence data focused on the genus Alloteuthis. It was based on 21 sequences belonging to nine species plus seven Alloteuthis sequences. The sequence lengths ranged from 1078 to $2776 \mathrm{bp}$ with a mean of $1901 \mathrm{bp}$. The length of the alignment was 2977 bp.

The seven 18S rDNA sequences obtained from specimens belonging to the genus Alloteuthis included specimens of all three morphotypes exhibiting morphological features of A. media, A. subulata and specimens that showed features of both. In the NJ analysis, Alloteuthis sequences appeared monophyletic with a bootstrap support of $95 \%$ (Fig. 5). The sequences belonging to the three different Alloteuthis morphotypes did not appear in separate clades corresponding to the morphological identification.

High bootstrap values of $\geq 98 \%$ were found for the species E. cirrhosa, R. macrosoma, T. eblanae and $L$. vulgaris. The $S$. tridens cluster was supported with a bootstrap value of $85 \%$. A low bootstrap value of only $64 \%$ was found for L. forbesii. Furthermore, the tree contained three singleton species, of which $S$. atlantica appeared closely related to the congeneric S. tridens..

\section{Discussion}

\section{Morphological species identification}

Species descriptions and identification keys provide easily applicable diagnostic features (De Heij and Goud 2010; Goud and De Heij 2012; Hayward and Ryland 1995), sometime including supplementary information about species' distribution, biology and ecology, which makes 
Table 3 Distance summary for each species including the distance to the nearest neighbor (NN) and species' barcoding gaps

\begin{tabular}{|c|c|c|c|c|c|c|c|}
\hline Species & $n$ & $\begin{array}{l}\text { Minimum distance } \\
(\%)\end{array}$ & $\begin{array}{l}\text { Maximum distance } \\
(\%)\end{array}$ & $\begin{array}{l}\text { Mean Dist } \pm \text { SD } \\
(\%)\end{array}$ & $\begin{array}{l}\text { Nearest } \\
\text { neighbor }\end{array}$ & $\begin{array}{l}\text { Distance to NN } \\
(\%)\end{array}$ & $\begin{array}{l}\text { Barcoding gap } \\
(\%)\end{array}$ \\
\hline Alloteuthis sp. & 29 & 0.00 & 0.61 & $0.17 \pm 0.14$ & L. forbesii & 12.25 & 11.64 \\
\hline Loligo forbesii & 23 & 0.00 & 0.30 & $0.04 \pm 0.06$ & L. vulgaris & 10.25 & 9.95 \\
\hline Loligo vulgaris & 3 & 0.46 & 2.13 & $1.42 \pm 0.86$ & L. forbesii & 10.25 & 8.12 \\
\hline $\begin{array}{l}\text { Todarodes } \\
\text { sagittatus }\end{array}$ & 2 & 0.33 & 0.33 & N/A & I. coindetti & 14.50 & 14.17 \\
\hline $\begin{array}{c}\text { Todaropsis } \\
\text { eblanae }\end{array}$ & 7 & 0.00 & 0.61 & $0.23 \pm 0.20$ & I. coindetti & 14.78 & 14.17 \\
\hline Illex coindetii & 4 & 0.00 & 0.33 & $0.16 \pm 0.17$ & S. tridens & 14.05 & 13.72 \\
\hline $\begin{array}{l}\text { Sepietta } \\
\quad \text { oweniana }\end{array}$ & 4 & 0.00 & 0.15 & $0.08 \pm 0.08$ & S. neglecta & 7.91 & 7.76 \\
\hline Sepietta neglecta & 1 & N/A & N/A & N/A & S. oweniana & 7.91 & N/A \\
\hline Sepiola atlantica & 2 & 0.00 & 0.00 & N/A & S. tridens & 3.41 & 3.41 \\
\hline Sepiola tridens & 16 & 0.00 & 0.00 & $0.00 \pm 0.00$ & S. atlantica & 3.41 & 3.41 \\
\hline Sepiola pfefferi & 1 & N/A & N/A & N/A & S. tridens & 8.59 & N/A \\
\hline $\begin{array}{l}\text { Rossia } \\
\text { macrosoma }\end{array}$ & 8 & 0.00 & 0.00 & $0.00 \pm 0.00$ & S. pfefferi & 14.84 & 14.84 \\
\hline Sepia elegans & 3 & 0.00 & 0.00 & $0.00 \pm 0.00$ & S. pfefferi & 17.47 & 17.47 \\
\hline Eledone cirrhosa & 5 & 0.00 & 0.49 & $0.24 \pm 0.17$ & S. pfefferi & 19.20 & 18.71 \\
\hline
\end{tabular}

$\mathrm{N} / \mathrm{A}=$ missing data due to small sample size

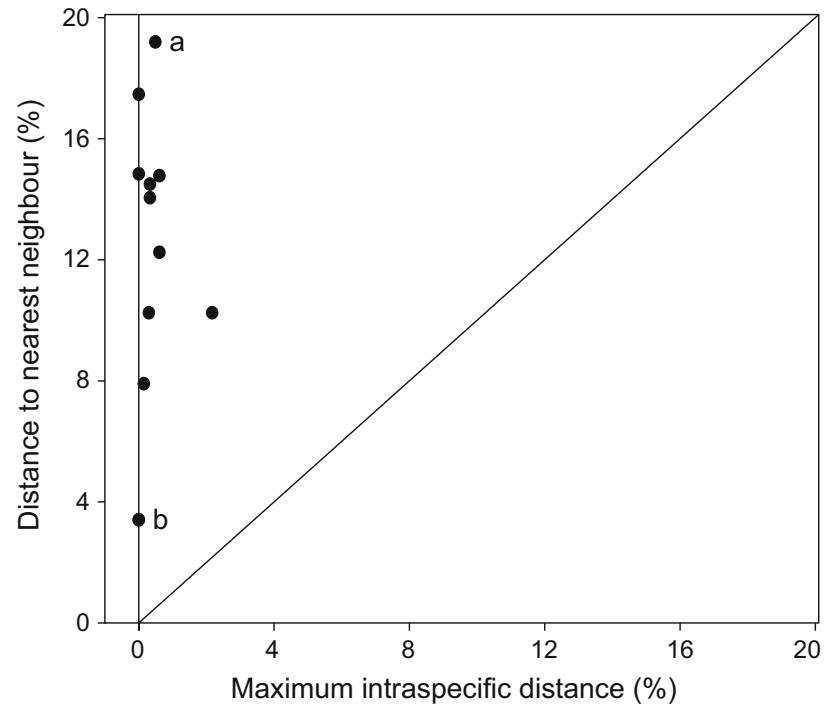

Fig. 3 Barcode Gap analysis. Each species is represented by a single dot. Along the 1:1 slope, the difference between maximum intraspecific distance and distance to the $N N$ nearest neighbor is zero. All dots are located above the 1:1 slope, indicating the presence of barcoding gaps; $\mathbf{a}$ indicates the species with the highest distance to its nearest neighbor, and $\mathbf{b}$ shows two overlapping data points, representing species with the lowest distance to a nearest neighbor

them a highly valuable source (Hastie et al. 2009; Pierce 2010; Jereb and Roper 2005, 2011; Marine Species Identification portal http://species-identification.org/). The two dichotomous keys used in this study differed substantially in their contents and integrity. While the key provided by the Marine Species Identification Portal (http://speciesidentification.org/) lacked only one species found in this study, the recently discovered S. tridens (Goud and De Heij 2012), the handbook of the marine fauna of Northwest Europe (Hayward and Ryland 1995) lacked the whole family Ommastrephidae, represented by 13 specimens in this study, and the genus Sepietta, represented by a total of five species in this study.

The subfamily Sepiolinae is a controversial group, in which species are difficult to distinguish from one another by external morphology, especially concerning females and juveniles (Groenenberg et al. 2009). Specific structures such as club sucker size or head and mantle width were inherently hard to measure due to their small size and their preservation in ethanol. However, this study confirmed the occurrence of five species belonging to the Sepiolinae in the North Sea-Sepietta oweniana d'Orbigny, 1841, S. neglecta, S. pfefferi, S. atlantica and the recently discovered S. tridens (De Heij and Goud 2010). These results strongly correspond to those proposed by Groenenberg et al. (2009), which confirmed the occurrence of the same five species that we found.

According to Jereb and Roper (2005), however, the Sepiolinae are represented by seven species in the North Sea-S. oweniana, S. neglecta, S. atlantica, S. pfefferi, Sepiola intermedia Naef, 1912, Sepiola aurantiaca Jatta, 1896 and Sepiola rondeletii Leach, 1817. The occurrence of S. intermedia and S. rondeletii in the North Sea is highly 


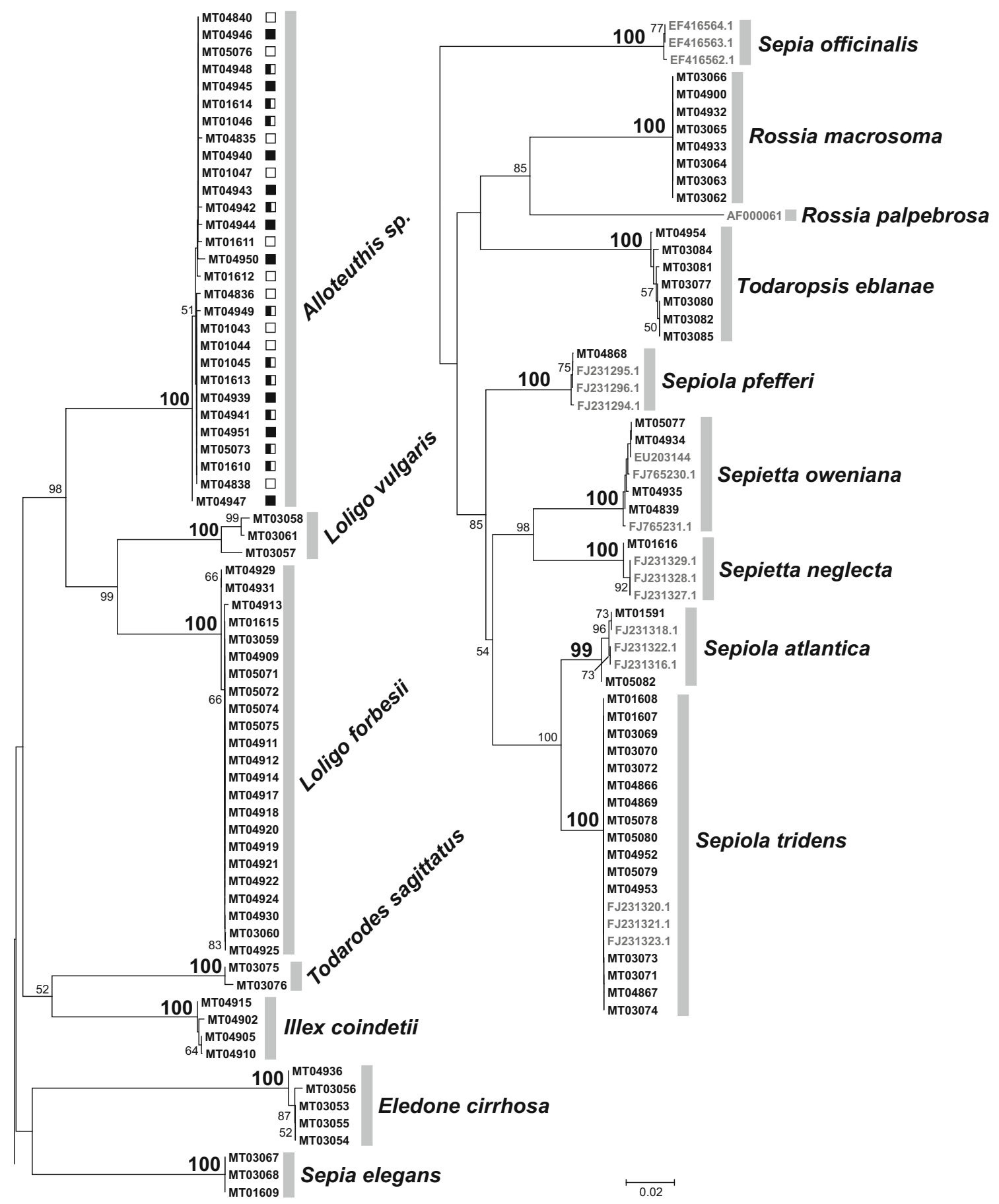

Fig. 4 Neighbor-joining tree (separated into two parts) based on uncorrected $p$-distances between $127 \mathrm{COI}$ barcodes including 19 GenBank sequences. Squares indicate different morphotypes of

doubted (Groenenberg et al. 2009; Goud and De Heij 2012). The present study supports these doubts, since neither $S$. intermedia nor $S$. rondeletii was found among the studied specimens.

Goud and De Heij (2012) recently examined the literature and specimens of S. pfefferi and S. aurantiaca, from museum collections and recently collected specimens, to
Alloteuthis; filled squares $=A$. subulata-like, blank $=A$. media-like, half filled $=$ intermediate morphotype. MT numbers represent DZMB sample identifiers

determine the validity of the two species. Although the original species descriptions are detailed, their analysis revealed inconsistencies in the older literature leading to the usage of both species names for specimens occurring in the northeast Atlantic, which clearly belonged to the same species (Goud and De Heij 2012). What started as two different species (Grimpe 1921) ended as synonyms. An 


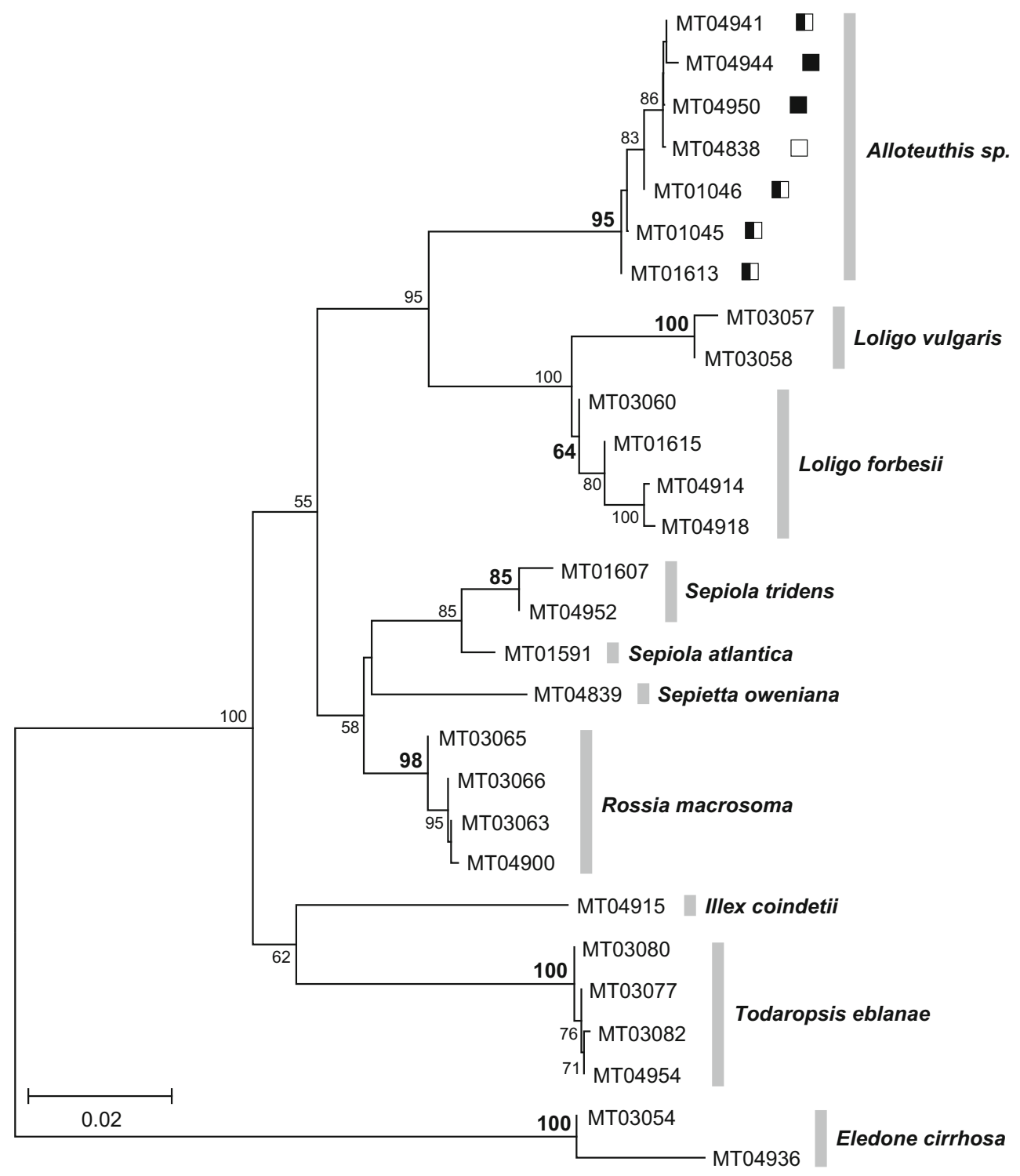

Fig. 5 Neighbor-joining tree based on uncorrected p-distances between $18 \mathrm{~S}$ rDNA sequences. Squares indicate different morphotypes of Alloteuthis; filled squares $=A$. subulata-like, blank $=A$.

additional complication is the loss of both species' holotypes; the $S$. aurantiaca-type samples were last seen in the 1970s, and the type specimens of S. pfefferi were most likely destroyed during World War II (Goud and De Heij 2012). Thus, a neotype for $S$. pfefferi has been designated (Goud and De Heij 2012). Furthermore, there were no specimens found, which were assignable to $S$. aurantiaca; instead, all studied Atlantic specimens were consistent with the descriptions for S. pefferi (Goud and De Heij 2012). The present study confirms these results. One specimen (MT04868) superficially resembled S. aurantiaca had to be assigned to $S$. pfefferi after the investigation of further features that distinguish $S$. pfefferi and S. aurantiaca (e.g., morphology of the first armpair and the tentacular clubs). media-like, half filled $=$ intermediate morphotype. MT numbers represent DZMB sample identifiers

Thus, it becomes evident that the five Sepiolinae species analyzed in the present study represent the complete North Sea species composition of Sepiolinae according to the current state of knowledge.

S. atlantica and its sister species $S$. tridens can be distinguished through morphology and geographic distribution (Groenenberg et al. 2009; De Heij and Goud 2010). S. atlantica occurs in the southern part of the North Sea, living in rather shallow regions, and S. tridens on the other hand is distributed in the northern parts of the North Sea, living in depths $>50 \mathrm{~m}$ (Groenenberg et al. 2009). The present study confirms this geographic delineation (Fig. 1).

The long-finned squid species of the genus Alloteuthis were the most challenging group in terms of morphological 
species identification. The present study revealed extreme difficulties to clearly distinguish $A$. media and A. subulata due to the lack of clear identifying features. A. media and A. subulata can be distinguished from other long-finned squids by a slender posterior extension of the mantle-the "tail". The length of the fins (which includes the tail) relative to the dorsal mantle length (DML) was a traditional measure to differentiate between A. media and A. subulata; specimens with a relative fin length above $50 \%$ DML were assigned to $A$. media, and specimens with a fin length below $50 \%$ DML were assigned to A. subulata. Recent studies have shown that this character is unreliable for species identification, since relative fin length increases with body length in mature squids (Anderson et al. 2008; Laptikhovsky et al. 2002). Furthermore, tail length differs between sexes with males having longer tails than females (Anderson et al. 2008).

Further diagnostic features are the central club sucker angle relative to club axis, the size of the largest club sucker relative to head width, maximum mantle length, arm length relative to mantle length, tentacle length, fin shape, the number of normal suckers on hectocotylus and the width of the tentacular club (e.g., Nesis 1987). One of these characters only applies to males, and others are difficult to measure, especially in preserved animals (e.g., tentacle length, head width). A more recent study discussed the difficulty of distinguishing A. media and A. subulata morphologically with the conclusion that these species could not be separated by traditional features (Laptikhovsky 2005). Another study revealed that only two of these characters are informative- the tentacular club width and central club sucker size (Anderson et al. 2008). Using a suite of possible diagnostic features, species assignable to A. media, A. subulata and a wide range of intermediate forms were found in this study.

As with S. aurantiaca and S. pfefferi, the holotypes of A. media and A. subulata have been lost and the original species descriptions are insufficient for distinguishing these two species (Anderson et al. 2008). It has also been proposed that these two species only represent different ecological forms or ontogenetic stages of one single species (Laptikhovsky et al. 2002).

The results of our molecular analysis support this hypothesis, as A. media and A. subulata could not be distinguished by mitochondrial COI DNA barcoding or nuclear 18S rDNA sequences. All studied North Sea Alloteuthis specimens assigned to three different morphotypes form just one distinct clade without any correlation to morphological features.

The systematics of Alloteuthis squids has been investigated using an integrative approach before (Anderson et al. 2008; Pilsits 2007). These two studies, analyzing the same dataset of Mediterranean and northeast Atlantic specimens, proposed different conclusions. Despite morphological discrepancies, both agree that one clade, including Mediterranean as well as northeast Atlantic specimens, can be assigned to A. media. Another clade, which is genetically distinct from the other and comprised of only three specimens from the Adriatic, is either assigned to $A$. subulata (Anderson et al. 2008) or to another cryptic species (Pilsits 2007).

A. media and A. subulata are highly sympatric, and both occur in the eastern Atlantic from the northwest coast of Africa to the North Sea and throughout the Mediterranean (Hastie et al. 2009). A. media is thought to prefer rather warm waters, like the Mediterranean, and only occasionally occurs in the Irish and southern North Sea. A. subulata however is supposed to be common in the North Sea and rare in the Mediterranean, where it is only found in deep waters (Nesis et al. 2003; Naef 1923). Recalling the species' geographic distributions reveals additional conflicts. A. media is thought to be common in the warm Mediterranean, which is true for both studies. Still, both found $A$. media to be very abundant in colder regions of the northeast Atlantic as well. More striking is the fact that $A$. subulata is suggested to be rare in the Mediterranean but common in the northeast Atlantic and the North Sea. Nevertheless, Anderson et al. (2008) assigned the Adriatic specimens to this species, which is thought to prefer cold and deep waters. This raises the questions whether the description of the geographic distribution for both species is accurate and whether the assignment of the Adriatic specimens by Anderson et al. (2008) is reliable.

The present study strongly supports the assumption that the genus Alloteuthis is only represented by a single species, at least in the North Sea. It could not be clarified whether this species is A. subulata or A. media.

Currently, the taxonomic status of A. media and $A$. subulata is untenable, and a redescription and designation of a neotype for both species would be essential to stabilize the taxonomy (Pierce 2010).

\section{DNA barcoding success}

The results of the barcoding analysis clearly demonstrated the efficiency of COI as a marker in separating different, even closely related, cephalopod species. All species formed distinct clusters which were supported by bootstrap values of $\geq 99 \%$. The correct morphological identification of the Sepiolida species was confirmed by additional sequence data obtained from GenBank. These sequences were chosen with caution and checked thoroughly before adding them to the analysis. During this process, it became evident that many sequences available from GenBank and BOLD are assigned to the wrong species. This is a general problem, which is prominent among mollusks 
(Groenenberg et al. 2009; Gasca and Janssen 2014). Thus, external data should be used with caution.

Our results demonstrate that DNA barcoding is still successful using shorter sequences as the suggested COI barcoding fragment. The sequence of one specimen of $T$. sagittatus (MT03075) had a length of $311 \mathrm{bp}$ and still clustered together with a conspecific sequence of the full barcode length. Several studies demonstrated that DNA barcoding is an effective method for the identification of cephalopod species (e.g., Dai et al. 2012; Kaneko et al. 2011; Allcock et al. 2011; Undheim et al. 2010). The genetic distances within and between species calculated in our study are similar to those found by others: Dai et al. (2012) found intraspecific distances (K2P distances) ranging from 0 to $1.4 \%$ (average $0.2 \%$ ) and interspecific distances ranging from 6.2 to $21.6 \%$ (average $17.1 \%$ ). Badhe et al. (2013) found an average genetic distance (K2P distances) of $0.2 \%$ within species, $10.6 \%$ within genus and $17.1 \%$ within family. Furthermore, intraspecific distances rarely exceed $2 \%$, and most are below $1 \%$ (Avise 2000), which is in concordance with our results.

Another quality criterion for successful DNA barcoding is the presence of the so-called barcoding gap. It can be interpreted in two ways, as a "global" and a "local" barcoding gap (Collins and Cruickshank 2013). The global barcoding gap is the gap between all intra- and interspecific distances, while the local one represents the gap between the highest intraspecific distance and the distance to the NN, and demonstrates the accuracy of DNA barcoding in delimiting species. The present study demonstrated the presence of both. The global barcoding gap of $1.18 \%$ genetic distance represents the difference between the highest intraspecific distance $(2.13 \%)$ and the lowest interspecific distance (3.31\%). Local barcoding gaps ranged from $3.41 \%$ up to $19.20 \%$. The species $S$. neglecta and S. pfefferi are only represented by a single specimen, and no intraspecific distance values could be considered for the calculation of barcoding gaps. However, these two species exhibited high distance values to their $\mathrm{NN}$ (8.59 and $7.91 \%$, respectively). Taking into account that intraspecific distances in cephalopods are usually below $1 \%$ and only slightly exceed that threshold, we anticipate the existence of a barcoding gap for these two species, though this assertion has yet to be verified by additional sequence data.

\section{Performance of 18S rDNA for species discrimination}

$18 \mathrm{~S}$ rDNA is widely used as a standard marker for different applications, such as phylogenetic studies and biodiversity analyses (Meyer et al. 2010). In the present study, $18 \mathrm{~S}$ was used to test its performance as alternative marker for species identification in particular concerning the genus Alloteuthis. Just like mitochondrial COI, nuclear DNA did not help to distinguish between the different morphotypes identified within the genus Alloteuthis (Figs. 4, 5). In all other cases, 18S was able to distinguish between species, as sequences belonging to the same species were clustered together. However, bootstrap support values were low in some cases ( $S$. tridens and L. forbesii), which may hinder unambiguous and reliable identification. Furthermore, $18 \mathrm{~S}$ cannot compete with COI from a technical point of view. Amplification and sequencing failures occurred frequently in $18 \mathrm{~S}$ compared to COI. This may be caused by pronounced secondary structures in GC-rich regions and high intramolecular forces within the 18S rDNA, both hampering standard amplification methods (Meyer et al. 2010).

\section{Sequence reference libraries}

The sequence data obtained in the present study were uploaded to BOLD and submitted to GenBank and can now be used as a sequence reference library for the identification of cephalopod species from the North and the Baltic Seas. Species identification based on molecular data can be very useful in cases where morphological features are hard to access or unreliable, or in cases where no morphological features are available at all, like in damaged specimens, juveniles, larvae or eggs. Thus, the global DNA barcode library BOLD is not only important for researchers working on systematics, but has widereaching benefits for fishery management, surveys and stock assessments (Strugnell and Lindgren 2007). The submission of sequences to BOLD is bound to explicit guidelines (Hanner 2005), in order to guarantee high reliability and quality of the data. Nevertheless, recent studies have shown that a high percentage of the cephalopod COI sequences on GenBank are most likely assigned to the wrong species (Groenenberg et al. 2009). This also affects BOLD as a consequence of uploaded data mined from GenBank. As a consequence, sequences assigned to the same species differed greatly from one another, or sequences assigned to different species showed very low divergence and clustered together (Groenenberg et al. 2009). Misidentification is a serious problem concerning the reliability of databases such as BOLD or GenBank. Sequences mined from any open-access database should be checked thoroughly concerning their reliability prior to any analysis, as done for the public sequences of Sepiolida used in the present study

Acknowledgments We thank Hermann Neumann, Matthias Schaber and Matthias Kloppmann for collecting samples and Gabrielle Miller for proofreading the manuscript. The project was funded by the Federal Ministry of Education and Research (Grant No. 03F0499A) and the Land Niedersachsen. 


\section{References}

Aguinaldo AMA, Turbeville JM, Linford LS, Rivera MC, Garey JR, Raff RA, Lake JA (1997) Evidence for a clade of nematodes, arthropods and other moulting animals. Nature 387:489-493. doi: $10.1038 / 387489 \mathrm{a} 0$

Allcock AL, Barratt I, Eléaume M, Linse K, Norman MD, Smith PJ, Steinke D, Stevens DW, Strugnell JM (2011) Cryptic speciation and the circumpolarity debate: a case study on endemic Southern Ocean octopuses using the COI barcode of life. Deep Sea Res Part II Top Stud Oceanogr 58:242-249. doi:10.1016/j.dsr2.2010. 05.016

Anderson FE, Pilsits A, Clutts S, Laptikhovsky V, Bello G, Balguerías E, Lipinski M, Nigmatulin C, Pereira JMF, Piatkowski U, Robin JP, Salman A, Tasende MG (2008) Systematics of Alloteuthis (Cephalopoda:Loliginidae) based on molecular and morphometric data. J Exp Mar Biol Ecol 364:99-109. doi:10.1016/j.jembe.2008.07.026

Avise JC (2000) Phylogeography: the history and formation of species. Harvard University Press, Cambridge

Badhe MR, Pavan-Kumar A, Gireesh-Babu P, Nandanpapwar P, Chaudhari A, Jaiswar AK, Krishna G, Lakra WS (2013) DNA barcoding of selected cephalopods from Indian coast. Indian J Anim Sci 83(8):862-866

Collins RA, Cruickshank RH (2013) The seven deadly sins of DNA barcoding. Mol Ecol Resour 13:969-975. doi:10.1111/17550998.12046

Conflitti IM, Shields GF, Currie DC (2012) A “complex" problem: delimiting sibling species boundaries in black flies (Diptera: Simuliidae). Can Entomol 144:323-336. doi:10.4039/tce.2012.29

Dai LN, Zheng XD, Kong LF, Li Q (2012) DNA barcoding analysis of Coleoidea (Mollusca: Cephalopoda) from Chinese waters. Mol Ecol Resour 12:437-447. doi:10.1111/j.1755-0998.2012. 03118.x

De Heij A, Goud J (2010) Sepiola tridens spec. nov., an overlooked species (Cephalopoda, Sepiolidae) living in the North Sea and north-eastern Atlantic Ocean. Basteria 74:51-62

Edgar RC (2004) MUSCLE: multiple sequence alignment with high accuracy and high throughput. Nucleic Acids Res 32:1792-1797. doi:10.1093/nar/gkh340

Efron B (1982) The Jackknife, the Bootstrap, and other resampling plans. Society for Industrial and Applied Mathematics (SIAM, 3600 Market Street, Floor 6, Philadelphia, PA 19104)

Felsenstein J (1985) Confidence limits on phylogenies: an approach using the bootstrap. Evolution 39:783-791. doi:10.2307/2408678

Field KG, Olsen GJ, Lane DJ, Giovannoni SJ, Ghiselin MT, Raff EC, Pace NR, Raff RA (1988) Molecular phylogeny of the animal kingdom. Science 239:748-753. doi:10.1126/science. 3277277

Folmer O, Black M, Hoeh W, Lutz R, Vrijenhoek R (1994) DNA primers for amplification of mitochondrial cytochrome $c$ oxidase subunit I from diverse metazoan invertebrates. Mol Mar Biol Biotechnol 3:294-299

Funk DJ, Omland KE (2003) Species-level paraphyly and polyphyly: frequency, causes, and consequences, with insights from animal mitochondrial DNA. Annu Rev Ecol Evol Syst 34:397-423. doi:10.1146/annurev.ecolsys.34.011802.132421

Gasca R, Janssen AW (2014) Taxonomic review, molecular data and key to the species of Creseidae from the Atlantic Ocean. J Molluscan Stud 80:35-42. doi:10.1093/mollus/eyt038

Goud J, De Heij A (2012) Mediterranean Sepiola aurantiaca Jatta, 1896, versus the NE Atlantic Sepiola pfefferi Grimpe, 1921 (Cephalopoda, Sepiolinae). Basteria 76:1-11

Grimpe G (1921) Teuthologische Mitteilungen VIII. Die Sepiolinen der Nordsee. Zoologischer Anzeiger 53:1-12
Groenenberg DSJ, Goud J, De Heij A, Gittenberger E (2009) Molecular phylogeny of North Sea Sepiolinae (Cephalopoda: Sepiolidae) reveals an overlooked Sepiola species. J Molluscan Stud 75:361-369. doi:10.1093/mollus/eyp032

Halanych KM (2004) The new view of animal phylogeny. Annu Rev Ecol Evol Syst 35:229-256. doi:10.1146/annurev.ecolsys.35. 112202.130124

Hammer $\varnothing$, Harper DAT, Ryan PD (2001) PAST: Paleontological statistics software package for education and data analysis. Palaeontol Electron 4(1)

Hanner R (2005) Data standards for BARCODE records in INSDC (BRIs). http://barcoding.si.edu/pdf/dwg_data_standards-final.pdf

Hastie LC, Pierce GJ, Wang J, Bruno I, Moreno A, Piatkowski U, Robin JP (2009) Cephalopods in the north-eastern Atlantic: species, biogeography, ecology, exploitation and conservation. In: Gibson RN, Atkinson RJA, Gordon JDM (eds) Oceanography and marine biology: an annual review, vol 47. Oceanography and Marine Biology. Crc Press-Taylor \& Francis Group, Boca Raton, pp 111-190

Hayward PJ, Ryland JS (1995) Handbook of the marine fauna of north-west Europe. Oxford University Press, Oxford

Hebert PDN, Cywinska A, Ball SL, DeWaard JR (2003a) Biological identifications through DNA barcodes. Proc R Soc B Biol Sci 270:313-321. doi:10.1098/rspb.2002.2218

Hebert PDN, Ratnasingham S, deWaard JR (2003b) Barcoding animal life: cytochrome $c$ oxidase subunit 1 divergences among closely related species. Proc R Soc B Biol Sci 270:S96-S99. doi:10.1098/rsbl.2003.0025

Hebert PDN, Stoeckle MY, Zemlak TS, Francis CM (2004) Identification of birds through DNA barcodes. PLoS Biol 2:1657-1663. doi:10.1371/journal.pbio.0020312

Hillis DM, Dixon MT (1991) Ribosomal DNA: molecular evolution and phylogenetic inference. Q Rev Biol 66:411-453. doi:10. 1086/417338

Jereb P, Roper CFE (2005) Cephalopods of the world: chambered nautiluses and sepioids (Nautilidae, Sepiidae, Sepiolidae, Sepiadariidae, Idiosepiidae, and Spirulidae). Food and Agriculture Organization of the United Nations

Jereb P, Roper CFE (2011) Cephalopods of the world. An annotated and illustrated catalogue of cephalopod species known to date vol 2. Food and Agriculture Organization of the United Nations

Kaneko N, Kubodera T, Iguchi A (2011) Taxonomic study of shallow-water octopuses (Cephalopoda: Octopodidae) in Japan and adjacent waters using mitochondrial genes with perspectives on octopus DNA barcoding. Malacologia 54:97-108

Knebelsberger T, Stöger I (2012) DNA extraction, preservation, and amplification. Methods Mol Biol 858:311-338

Laakmann S, Gerdts G, Erler R, Knebelsberger T, Arbizu PM, Raupach MJ (2013) Comparison of molecular species identification for North Sea calanoid copepods (Crustacea) using proteome fingerprints and DNA sequences. Mol Ecol Resour 13:862-876. doi:10.1111/1755-0998.12139

Laptikhovsky V (2005) Morphological changes at maturation and systematics in the squid genus Alloteuthis. Phuket Mar Biol Center Res Bull 66:187-193

Laptikhovsky V, Salman A, Onsoy B, Katagan T (2002) Systematic position and reproduction of squid of the genus Alloteuthis (Cephalopoda : Loliginidae) in the eastern Mediterranean. J Mar Biol Assoc UK 82:983-985. doi:10.1017/s0025315402006483

Meyer CP, Paulay G (2005) DNA barcoding: error rates based on comprehensive sampling. PLoS Biol 3:2229-2238. doi:10.1371/ journal.pbio.0030422 e422

Meyer A, Todt C, Mikkelsen NT, Lieb B (2010) Fast evolving 18S rRNA sequences from Solenogastres (Mollusca) resist standard PCR amplification and give new insights into mollusk 
substitution rate heterogeneity. BMC Evol Biol. doi:10.1186/ 1471-2148-10-70

Moore PB, Steitz TA (2002) The involvement of RNA in ribosome function. Nature 418:229-235. doi:10.1038/418229a

Naef A (1923) Die Cephalopoden. In: Fauna and Flora of the Bay of Napoli. vol 1, pp 543-632

Nesis KN (1987) Cephalopods of the world. TFH Publications, Neptune City

Nesis KN, Zuev GV (Compiled by Sweeney MJ) (2003) Selected english translations of publications on Cephalopods: squid (biology and fishing). vol Bd. 2. Smithsonian Institution Libraries, $\mathrm{p} 434$

Pierce GJ (2010) Cephalopod biology and fisheries in Europe. ICES cooperative research report. International Council for the Exploration of the Sea, Copenhagen

Pilsits A (2007) Phylogeny and population genetics of Allotheuthis (Loliginidae) and Discovery of a cryptic species honors Theses paper 327

Ratnasingham S, Hebert PDN (2007) BOLD: the barcode of life data system (www.barcodinglife.org). Mol Ecol Notes 7:355-364. doi:10.1111/j.1471-8286.2006.01678.x

Raupach MJ, Astrin JJ, Hannig K, Peters MK, Stoeckle MY, Wagele JW (2010) Molecular species identification of Central European ground beetles (Coleoptera: Carabidae) using nuclear rDNA expansion segments and DNA barcodes. Front Zool. doi:10. $1186 / 1742-9994-7-26$
Saitou N, Nei M (1987) The neighbor-joining method: a new method for reconstructing phylogenetic trees. Mol Biol Evol 4:406-425

Song H, Buhay JE, Whiting MF, Crandall KA (2008) Many species in one: DNA barcoding overestimates the number of species when nuclear mitochondrial pseudogenes are coamplified. Proc Natl Acad Sci USA 105:13486-13491. doi:10.1073/pnas.0803076105

Strugnell JM, Lindgren AR (2007) A barcode of life database for the Cephalopoda? Considerations and concerns. Rev Fish Biol Fish 17:337-344. doi:10.1007/s11160-007-9043-0

Tamura K, Peterson D, Peterson N, Stecher G, Nei M, Kumar S (2011) MEGA5: molecular evolutionary genetics analysis using maximum likelihood, evolutionary distance, and maximum parsimony methods. Mol Biol Evol 28:2731-2739. doi:10. 1093/molbev/msr121

Telford MJ, Wise MJ, Gowri-Shankar V (2005) Consideration of RNA secondary structure significantly improves likelihoodbased estimates of phylogeny: examples from the bilateria. Mol Biol Evol 22:1129-1136. doi:10.1093/molbev/msi099

Undheim EAB, Norman JA, Thoen HH, Fry BG (2010) Genetic identification of Southern Ocean octopod samples using mtCOI. C R Biol 333:395-404. doi:10.1016/j.crvi.2010.02.002

Wollscheid E, Wagele H (1999) Initial results on the molecular phylogeny of the nudibranchia (Gastropoda, Opisthobranchia) based on 18S rDNA data. Mol Phylogenet Evol 13:215-226. doi:10.1006/mpev.1999.0664 